\title{
Rapid Activation of Plasticity-Associated Gene Transcription in Hippocampal Neurons Provides a Mechanism for Encoding of One-Trial Experience
}

\author{
Teiko Miyashita, ${ }^{1}$ Stepan Kubik, ${ }^{1,3}$ Nahideh Haghighi, ${ }^{1}$ Oswald Steward, ${ }^{1,2}$ and John F. Guzowski ${ }^{1}$ \\ ${ }^{1}$ Department of Neurobiology and Behavior, Center for the Neurobiology of Learning and Memory and ${ }^{2}$ Reeve-Irvine Research Center, Departments of \\ Anatomy and Neurobiology, and Neurosurgery, University of California, Irvine, Irvine, California 92697, and ${ }^{3}$ Department of Neurophysiology of Memory, \\ Institute of Physiology, Academy of Sciences of the Czech Republic, 14220 Prague, Czech Republic
}

The hippocampus is hypothesized to support rapid encoding of ongoing experience. A critical prerequisite for such function is the ability to readily recruit enduring synaptic plasticity in hippocampal neurons. Hippocampal long-term potentiation (LTP) and memory consolidation require expression of the immediate-early gene (IEG) Arc. To determine whether Arc transcription could be driven by limited and controlled behavioral experience, we used a rectangular track paradigm. In past electrophysiological studies, pyramidal neurons recorded from rats running in one direction on similar tracks typically exhibited a single firing field. Using fluorescence in situ hybridization, we show that the behavioral activity associated with a single lap around the track was sufficient to trigger $A r c$ transcription in complete CA3 neuronal ensembles, as predicted given the role of CA3 in one-trial learning. In contrast, Arc transcription in CA1 ensembles was recruited incrementally, with maximal activation achieved after four laps a day for 4 consecutive days. To test whether Arc transcription is linked to learning and plasticity, or merely elicited by location-specific firing, we inactivated the medial septum, a treatment that compromises hippocampus-dependent learning and LTP but spares location-specific firing in CA1 neurons. Septal inactivation abolished track training-induced Arc transcription in CA1 and CA3 neurons, showing that Arc transcription requires plasticity-inducing stimuli. Accordingly, LTP induction activated Arc transcription in CA1 neurons in vivo. These findings demonstrate for the first time that a single brief experience, equivalent to a single crossing of a firing field, can trigger IEG expression required for long-term plasticity in the hippocampus.

Key words: IEG; place cell activity; medial septum; theta oscillations; hippocampus; FISH

\section{Introduction}

A critical function of the hippocampus is to rapidly encode associations of complex stimuli to capture experience into memory (Morris and Frey, 1997). The CA3 subfield, with its recurrent collateral projections, is particularly adept at forming associations rapidly, enabling memory after as little as a single trial (Lee and Kesner, 2002; Nakazawa et al., 2003). Such rapid memory formation would likely require (1) efficient recruitment of neurons comprising an entire CA3 ensemble and (2) activation of cellular plasticity mechanisms enabling lasting modification of synapses in those neurons, by a single presentation of stimuli. Because of their regulation by neural activity and obligate role in hippocampal neuroplasticity (for review, see Kubik et al., 2007; Miyashita et al., 2008), immediate-early genes (IEGs) provide a

Received Sept. 24, 2008; revised Nov. 18, 2008; accepted Dec. 3, 2008.

This work was supported by National Institutes of Health Grants MH060123 (J.F.G.) and MH733307 (T.M.). We thank Levi Maes, Kristopher Marjon, Maureen McGarry, Christine Petrossian, Megan Ikeda, and Alex Pevzner for technical assistance. We also thank Gail Lewandowski, Alex Pevzner, Marcelo Wood, and anonymous reviewers for discussion and comments on a previous version of this manuscript.

Correspondence should be addressed to John F. Guzowski, 108 Bonney Research Labs, Irvine, CA 92697-3800. E-mail: john.g@uci.edu.

DOI:10.1523/JNEUROSCI.4588-08.2009

Copyright $\odot 2009$ Society for Neuroscience $\quad$ 0270-6474/09/290898-09\$15.00/0 window into both elements of this hypothesis. In particular, the IEG Arc (also known as Arg3.1) is regulated in hippocampal CA1 and CA3 neurons in a context-specific manner that qualitatively and quantitatively mirrors place cell firing (Guzowski et al., 1999, 2004; Vazdarjanova and Guzowski, 2004). Accordingly, detection of Arc delineates neural ensembles activated by discrete experiences. At a cellular level, Arc can be targeted to active synapses (Steward and Worley, 2001; Moga et al., 2004) in which it participates in molecular mechanisms of synaptic plasticity (Chowdhury et al., 2006; Shepherd et al., 2006; Messaoudi et al., 2007). Consistent with these findings, Arc knock-out mice do not express lasting long-term potentiation (LTP) or long-term depression in hippocampus, and these animals are impaired for long-term memory in several behavioral tasks (Plath et al., 2006). In addition, direct knockdown of Arc expression in hippocampus blocks LTP maintenance and impairs memory consolidation for spatial water maze and inhibitory avoidance training (Guzowski et al., 2000; McIntyre et al., 2005; Messaoudi et al., 2007).

The current study investigates the dynamics of CA3 and CA1 neuronal ensemble recruitment in rats given brief behavioral experience on a closed rectangular track using fluorescence in situ hybridization (FISH) to Arc RNA. Closed tracks are used in unit recording studies of place cell activity, and it has been shown that 
a
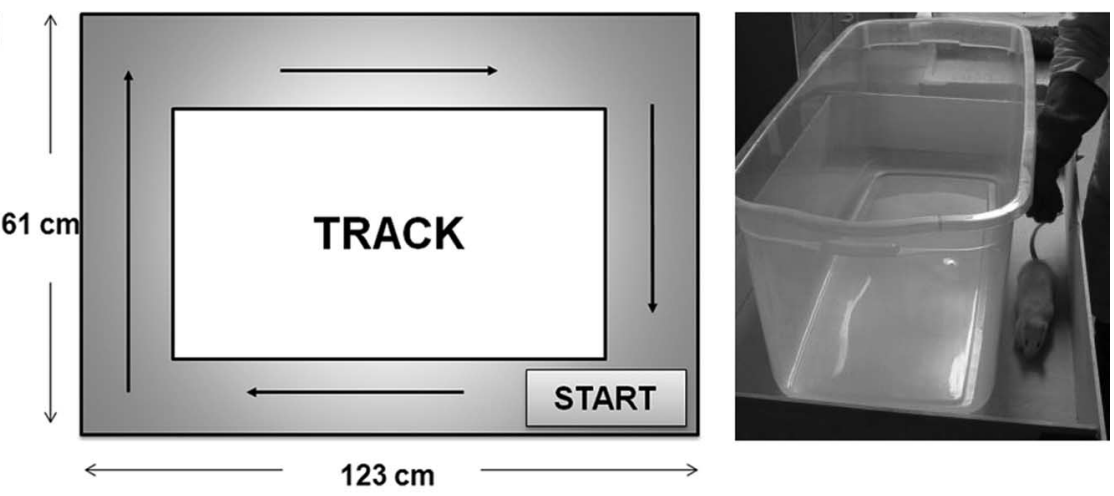

b.

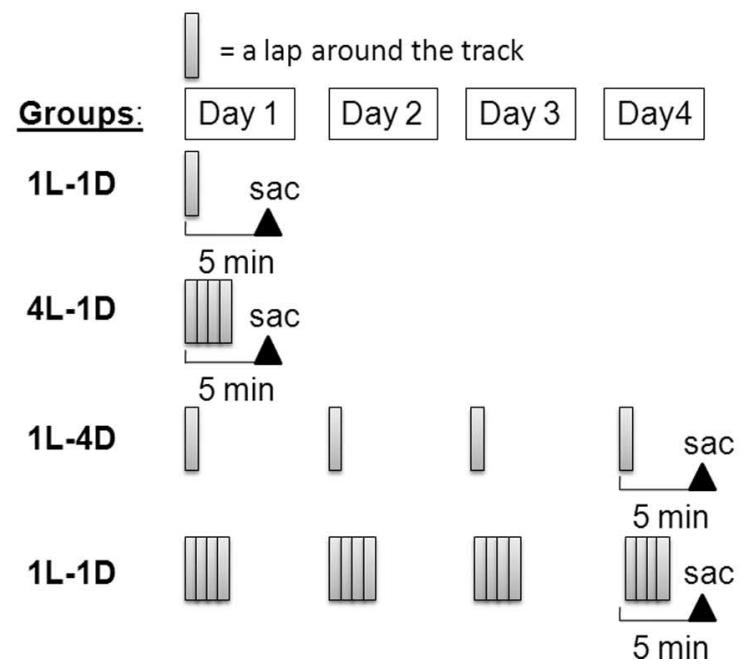

Figure 1. Track training design. $\boldsymbol{a}$, A schematic and photograph of the track training procedure. At each training session, a rat was placed on the starting corner of the track and guided to walk in the same direction. $\boldsymbol{b}$, A schematic of the experimental design. Rats walked around the track in one direction either once or four times on a single day or over 4 consecutive days. sac, The time point at which rats were killed.

any given hippocampal pyramidal neuron typically has no more than one firing field on a given track (Mehta et al., 1997). A single lap around such a track, then, provides maximally one traverse through the firing field of a cell. By manipulating the number of laps, we addressed the unresolved question as to whether a single passage through the firing field of a pyramidal neuron is sufficient to activate Arc transcription or whether multiple traverses are necessary (Acsády and Káli, 2007), and whether CA3 and CA1 differ in this respect. To test whether Arc transcription reflects plasticity and learning rather than merely location-specific firing, we inactivated the medial septum, which dissociates hippocampal cell firing from plasticity, and examined its impact on Arc induction by track training.

Here, we show experience limited to a single lap on the track activated $A r c$ transcription in complete CA3 ensembles, whereas $\mathrm{CA} 1$ ensembles required additional experience for full activation. Furthermore, medial septal inactivation abolished experiencedependent Arc transcription in both CA3 and CA1, confirming the link between Arc transcription and plasticity. Thus, a single presentation of brief experience can trigger Arc transcription in complete CA3 ensembles, enabling neuroplastic changes involved in the rapid encoding of ongoing experience.

\section{Materials and Methods}

Behavioral handling procedures. A total of 82 3-month-old male Sprague Dawley rats (Charles River/Harlan) were handled $5 \mathrm{~min} / \mathrm{d}$ for $5 \mathrm{~d}$ before each experiment [43 rats in the track/FISH study, 25 rats in track/septal inactivation study, and 14 rats in track/reverse transcription-quantitative PCR (RT-qPCR) study]. All animal handling and surgical procedures complied with National Institutes of Health guidelines and were approved by the Institutional Animal Care and Use Committee of the University of New Mexico and University of California, Irvine.

Rectangular track and training procedures. The rectangular track consisted of a table $(123 \times 61 \mathrm{~cm})$ with $14-\mathrm{cm}$-high plywood walls and a plastic container $(90 \times 30 \mathrm{~cm})$ centered on the table, allowing a passage $(\sim 15 \mathrm{~cm}$ width $)$ around the table (Fig. 1a). For a session, each rat was transported on a cart from the holding room to the experimental room in its covered home cage. Rats were always released from the same starting corner of the track and freely traversed in the same direction guided by the experimenter's hand. The different behavioral groups are described in Results (Fig. 1b). The same training procedure was used for all track experiments. Rats that completed training in $<5$ min were returned to the home cage for the remaining interval to ensure that all rats were killed no sooner than $5 \mathrm{~min}$ after the start of training. Rats that took longer than $5 \mathrm{~min}$ for their training were allowed to complete their laps and were then killed immediately. All rats were deeply anesthetized with isoflurane and decapitated.

Cannula implantation surgeries. One 23 gauge stainless steel cannula was stereotaxically implanted under isoflurane anesthesia just above the medial septum [in mm: anteroposterior $(\mathrm{AP}),+0.7$; mediolateral $(\mathrm{ML}), 0.0$; dorsoventral (DV), -5.0 from bregma]. The cannula was equipped with a stainless steel stylet to protect the lumen from obstruction. The cannula was cemented to the skull using two anchoring screws and dental cement. All rats were given at least a 1 week recovery period before the behavioral training began. The infusion site was confirmed on coronal sections containing the medial septum and stained with cresyl violet. Seven rats (one from VEH-CC and two each from TETRA-CC, VEH-TRACK, and TETRA-TRACK) were excluded from analysis based on histological findings.

Septal inactivation. During the infusion procedure, the rats were gently handled, the stylet was removed, and a stainless steel injector (30 gauge) protruding $1.0 \mathrm{~mm}$ beyond the tip of the guide cannula was inserted. The injector was connected to a $10 \mu \mathrm{l}$ Hamilton syringe via polyethylene tubing. A total of $0.5 \mu \mathrm{l}$ of either $2 \%$ tetracaine (TETRA) (Sigma) or PBS [vehicle (VEH)] was injected over 1 min using a minipump (KD Scientific). The injector was left in place for another minute and then was slowly withdrawn, and the stylet was replaced.

FISH. After decapitation, the brains were quickly $(<2 \mathrm{~min})$ removed and flash frozen in isopentane (at approximately $-50^{\circ} \mathrm{C}$ ). One right hemisphere from one animal of each behavioral group was used to make a tissue block for cryosectioning (Guzowski et al., 1999; Vazdarjanova and Guzowski, 2004). Use of such tissue blocks helps control for slideto-slide variation in signal-to-noise ratio of signal detection that is common in histochemical procedures such as FISH, as described here. In this way, any variation will affect all brains similarly and not lead to systematic errors that could potentially only affect one group. The tissue was sectioned at $20 \mu \mathrm{m}$, and the sections containing the dorsal hippocampus (AP, approximately $-3.6 \mathrm{~mm}$ from bregma) were randomly selected and processed for FISH as described in detail previously (Guzowski et al., 1999; Vazdarjanova and Guzowski, 2004). Briefly, digoxigenin-labeled antisense $A r c$-intron-enriched riboprobes (for details, see Guzowski et al., 2006) were hybridized on tissue sections overnight at $56^{\circ} \mathrm{C}$ and de- 
tected with the use of anti-digoxigenin-HRP conjugate (Roche) and a commercial cyanine-3 tyramide signal amplification kit (TSA-CY3; PerkinElmer Life Sciences). Sections were counterstained for nuclei with 4',6'-diamidino-2-phenylindole (Invitrogen).

Microscopy, image acquisition, and analysis. Confocal image stacks of CA1 and CA3 from coronal sections were collected at a $Z$ frequency of 0.5 $\mu \mathrm{m}$ with a Zeiss Axiovert $200 \mathrm{M}$ inverted microscope using a $20 \times$ apochromat objective (numerical aperture 0.8), CARVII spinning disk confocal unit (BD Biosciences), CCD camera (ORCA ERII; Hamamatsu), and IPLab 4.0 software (BD Biosciences) (see Figs. 3a,b, 5b,c, 6d) (supplemental Figs. S3, S4, available at www.jneurosci.org as supplemental material). All settings were optimized for detection of bright intranuclear foci of Arc transcription for each slide with care to avoid saturation and were kept constant for all images from that slide. Threshold detection cell counts with a chimeric subjective/objective approach were performed (Guzowski et al., 2006) by an experimenter blind to the behavioral conditions. During the offline analysis, nuclei within the middle $20 \%$ of confocal stack images were traced, and Arc signal parameters (integrated, average, maximum, and minimum intensities) within each traced region were exported to Microsoft Excel. Then, cell nuclei were automatically defined as $A r c$-positive $\left(\mathrm{Arc}^{+}\right)$or $A r c$-negative $\left(A r c^{-}\right)$based on input threshold values for integrated and maximum signal intensities, which were applied to all images from a given slide. Given that there is slide-toslide variation in signal intensity and background and that the presented data derive from many slides collected over several months, it is necessary to establish the positive foci threshold for each slide. Within a given slide, then, all "positive" cells will have an integrated signal above threshold and negative cells a value below this threshold. As seen in supplemental Figure 4 (available at www.jneurosci.org as supplemental material), even with slide-to-slide variation, there are easily identified peaks for positive cells in CA3 and CA1 in frequency distribution histograms of single cell intensities. The number of $\mathrm{Arc}^{+}$nuclei was then compiled for the CA1 and $\mathrm{CA} 3$ region of each rat. In the tetracaine-medial septum experiment, CA3 confocal images were projected onto a single plane and analyzed using an automated image analysis program, Farsight (Lin et al., 2003; Chawla et al., 2004).

Two fields for CA1 and three fields for CA3 from each brain section on a slide and four brain sections per animal were analyzed. The values are reported as the percentage of $\mathrm{Arc}^{+}$cells per total counted cells for each rat. An average of 657 CA1 cells and 557 CA3 cells were counted per animal. In the septal inactivation study, an average of 1012 CA1 cells and 753 CA3 cells were analyzed from five brain sections per animal.

LTP induction. Six adult female Sprague Dawley rats were anesthetized with urethane as described previously (Steward and Worley, 2001). A glass micropipette recording electrode was positioned in the CA1 region of the hippocampus on one side (in mm: AP, -3.5 ; ML, 2.5; DV, $\sim 2.2$ from the cortical surface), with the final depth being adjusted to record the negative-going EPSP in stratum radiatum. A monopolar stimulating electrode was positioned in the contralateral CA3 region (in mm: AP, -4.5 ; ML, 3.5; and DV, -2.5 with the final position adjusted to elicit the maximal negative-going response). The animal was allowed to equilibrate for $1-2 \mathrm{~h}$ without stimulation. In three animals, test stimulation was delivered at a rate of one pulse per every $10 \mathrm{~s}$ to determine baseline response amplitude, and LTP was induced by delivering two $100 \mathrm{~Hz}$ trains lasting $500 \mathrm{~ms}$ (50 pulses), separated by $30 \mathrm{~s}$. Test stimulation was delivered for $5 \mathrm{~min}$ to assess LTP magnitude (see Fig. 6). Three other animals received only the test stimulation.

RNA extraction. Unilateral (right) dorsal hippocampal tissue from each rat was homogenized in Trizol (Invitrogen) using a PowerGen 35 homogenizer (VWR). RNA was extracted by addition of chloroform, followed by transferring to phase-lock gel tubes (Eppendorf). Total RNA was precipitated from the aqueous phase with $100 \%$ ethanol, 0.1 vol of 3 M sodium acetate ( $\mathrm{pH}$ 5.2), and glycoblue (Ambion). The pellet was then washed with 70\% ethanol, dried, and resuspended in RNase-free sterile water. Residual DNA was removed using the Turbo DNA-free kit (Ambion). RNA cleanup was performed by Rneasy MinElute kit (Qiagen) according to the instructions of the manufacturer, followed by quantification by optical density measurement at 260 and $280 \mathrm{~nm}$ using Ultrospec 2000 spectrophotometer (Pharmacia Biotech).
cDNA constructs. cDNA was generated from purified RNA using the RETROscript kit (Ambion) according to the instructions of the manufacturer. In short, $2 \mu \mathrm{g}$ of total RNA was reverse transcribed with $100 \mathrm{U}$ of Moloney murine leukemia virus-RT in a $20 \mu \mathrm{l}$ reaction using $5 \mu \mathrm{M}$ random decamers. Mouse liver RNA template $(0.5 \mathrm{mg} / \mathrm{ml})$ provided by the kit was used as positive control for cDNA synthesis. Additional control for genomic contamination in quantitative PCR was determined using $2 \mu \mathrm{g}$ RNA samples in parallel but without reverse transcriptase. Reverse-transcription conditions were $44^{\circ} \mathrm{C}$ for $1 \mathrm{~h}, 50^{\circ} \mathrm{C}$ for $10 \mathrm{~min}$, followed by $92^{\circ} \mathrm{C}$ for $10 \mathrm{~min}$ to heat inactivate the reverse transcriptase.

$R T-q P C R$. RT-qPCR was performed with intron-specific primers for Arc, zif268, and c-fos cDNA samples (see below for validation of primers). RT-qPCR was performed using $12.5 \mu \mathrm{l}$ of Quantitect SYBR master mix (Qiagen), $2.5 \mu \mathrm{l}$ of $3 \mu \mathrm{M}$ primer set, and $10 \mu \mathrm{l}$ of $5 \mathrm{ng} / \mu \mathrm{l} \mathrm{cDNA}$. All RT-qPCR was performed in triplicate. Reactions were performed in the Eppendorf Mastercycler realplex with an initial Taq polymerase activation at $95^{\circ} \mathrm{C}$ for $15 \mathrm{~min}$, followed by 40 subsequent cycles of $95^{\circ} \mathrm{C}$ for $15 \mathrm{~s}$, $59^{\circ} \mathrm{C}(A r c), 56^{\circ} \mathrm{C}(\mathrm{c}-f o s)$, or $55^{\circ} \mathrm{C}(z i f 268)$ for $30 \mathrm{~s}$, and $72^{\circ} \mathrm{C}$ for $30 \mathrm{~s}$. The efficiency of each primer set was determined using a serial dilution of standard plasmid DNA. Arc, zif268, and c-fos products were cloned using the TA cloning kit (Invitrogen) following the instructions of the manufacturer and sequenced to confirm the appropriate sequence amplification. Control reactions without template were performed for each primer set for a given PCR run. Data were normalized to $\beta$-actin run in parallel samples. Relative quantification of gene expression was determined by the comparative cycle threshold $\left(\mathrm{C}_{\mathrm{t}}\right)$ method. The fold change in each sample was determined relative to the cage control samples (CC). The amount of target was calculated by the formula $2^{-\Delta \Delta \mathrm{Ct}}$. Relative intron RNA levels, normalized to CC, were calculated as follows: $2^{-[\text {DeltaCt(sample) }-\operatorname{DeltaCt}(c c)]}=2^{- \text {DeltaCt }}$, where DeltaCt equals $\mathrm{C}_{\mathrm{t}}($ Arc, zif268, or $\mathrm{c}-$ fos $)-\mathrm{C}_{\mathrm{t}}($ actin $)$.

The following primers were used: $\operatorname{Arc}$ (GenBank accession number U19866), intron: forward, CTTGCCTCCTGTCCTGAGC; reverse, AGAAAGCAGCAGCAAGATGG; zif268 (GenBank accession number J04154), intron: forward, AATCCCCCTTCGTGACTACC; reverse, GCAAGGATGGAGGGTTGG; c-fos (GenBank accession number DQ089699), intron: forward, AGGTGAGTTTGGCTTTGTGC; reverse, TCAGACAAGTCCTGGGTTCC.

Validation of primers. To validate that primers were specific to intronic regions of primary transcript for Arc, zif268, and c-fos, rats were trained on the track (four laps, 1 day) and killed at 5 and $30 \mathrm{~min}$, and $3 \mathrm{~h}$ after the training $(n=3$ each). The CC were killed directly from the home cage. RNA was extracted from tissue punches from the bilateral dorsal hippocampi from these animals, and RT-qPCR analysis was performed. Significant fold differences from the CC group were only detected in the 5 min group (supplemental Fig. S1, available at www.jneurosci.org as supplemental material), indicating that the primers specifically detected intron-containing primary transcripts.

Statistical analyses. The main effect of behavioral treatment in FISH and RT-qPCR assays was determined by one-way ANOVA. When the main effect was significant at the $p<0.05$ level, additional comparisons between groups were conducted with Scheffe's $F$ post hoc test (Statview software). Kruskal-Wallis test was used in foci intensity analysis to examine the effects of behavioral condition (one lap, 1 day; four laps, $1 \mathrm{~d}$; one lap, $4 \mathrm{~d}$; and four laps, $4 \mathrm{~d})$ within each cell classification $\left(\mathrm{Arc}^{+}\right.$vs $A r C^{-}$). When appropriate, Mann-Whitney $U$ test was used to compare mean ranks of signal intensity between two behavioral groups. Two-way ANOVA was used to analyze the effects of behavioral condition (CC vs TRACK) and infusion (VEH vs TETRA) in the septal inactivation study. When appropriate, Scheffé's post hoc tests were used. Pearson's correlation coefficient was used to evaluate the relationship between proportion of $\mathrm{Arc}^{+}$neurons and either the number of laps or time on the track.

\section{Results}

Activation of Arc, zif268, and c-fos transcription by limited experience on the track revealed by RT-qPCR

To examine whether IEGs are activated by a brief behavioral experience, we trained rats to walk around a rectangular track in one direction (Fig. 1a) either once or four times on a single day or 


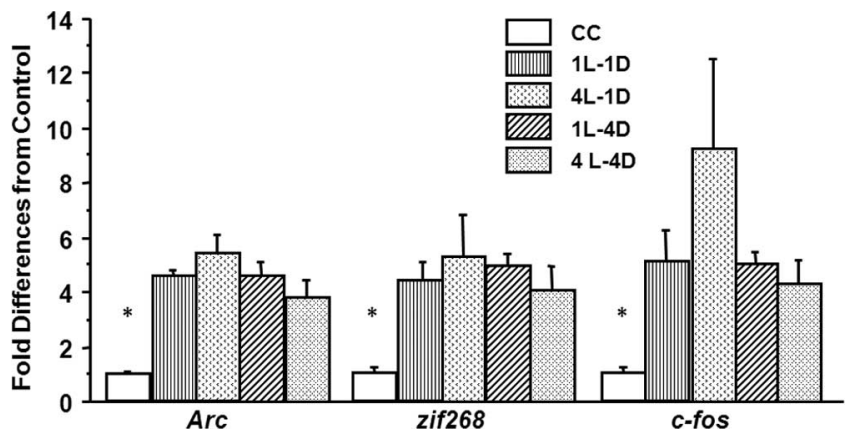

Figure 2. Activation of $A r c$, zif268, and c-fos transcription in dorsal hippocampus by limited experience on the track revealed by RT-qPCR. For all genes analyzed, training on the track induced significantly higher levels of primary transcript relative to the caged controls $\left({ }^{*} p<\right.$ 0.05). Of note, the fold differences between the track-trained groups did not differ for any of the genes. $n=3$, except for $4 \mathrm{~L}-1 \mathrm{D}(n=2)$.

over 4 consecutive days, and then performed RT-qPCR analysis for three IEGs implicated in synaptic plasticity (Arc, c-fos, and zif268) (Abraham et al., 1991; Bozon et al., 2002). Fourteen adult male rats were divided into five experimental groups: CC $(n=3)$, rats were killed directly from their home cages in the holding room; one lap, $1 \mathrm{~d}(1 \mathrm{~L}-1 \mathrm{D} ; n=3)$, rats walked around the track once on a single day; four laps, $1 \mathrm{~d}(4 \mathrm{~L}-1 \mathrm{D} ; n=2)$, rats walked around the track four times on a single day; one lap, $4 \mathrm{~d}(1 \mathrm{~L}-4 \mathrm{D}$; $n=3$ ), rats walked around the track once per day for 4 consecutive days; and four laps, $4 \mathrm{~d}(4 \mathrm{~L}-4 \mathrm{D} ; n=3)$, rats walked around the track four times a day for 4 consecutive days (Fig. 1b). Because behavioral induction of $A r c$ transcription peaks at $5 \mathrm{~min}$ and declines rapidly thereafter (Vazdarjanova et al., 2002), the training was limited to four laps per day to maximize detection of Arc induced specifically by the rats' behavior on the track. Rats were killed 5 min after the beginning of the last training session.

RNA was extracted from the right dorsal hippocampus and used for subsequent RT-qPCR analysis. To differentiate primary transcript induced by training from mature mRNA present earlier, we designed primer sets to amplify intronic sequences for $A r c, c-f o s$, and zif268 present only in the primary transcripts [for validation of primers, see Materials and Methods and supplemental Fig. S1 (available at www.jneurosci.org as supplemental material)]. An actin primer set was used for normalization of samples and calculation of relative fold changes in RNA expression. Arc expression in all rats that were trained on the track was dramatically increased relative to the CC group $\left(F_{(4,9)}=12.65\right.$, $p<0.001$, one-way ANOVA) (Fig. 2) but did not differ from each other $(p>0.05)$. Similar to Arc, zif268 and c-fos were upregulated in all behavioral groups relative to the CC group (zif268, $F_{(4,9)}=5.47, p<0.05$; c-fos, $F_{(4,9)}=5.09, p<0.05$ ) (Fig. 2). These data demonstrate that IEGs implicated in synaptic plasticity are activated with a brief behavioral experience such as a single lap on the track and inferentially by a single bout of neural stimuli (activity associated with a single traverse of a firing field).

\section{Dynamics of hippocampal ensemble recruitment in the behaving rat: robust activation of $\mathrm{CA} 3$ by limited experience and incremental activation of CA1 with extended experience} Although the RT-qPCR data helped address the impact of brief experience on IEG expression throughout the dorsal hippocampus, it lacked the cellular specificity necessary to investigate potential differences in ensemble recruitment dynamics between CA3 and CA1 regions. To achieve this goal, we again used the track paradigm but instead assayed Arc transcription using a sen- sitive FISH methodology. We trained rats in the similar manner as the previous experiment (Fig. 1a) with the addition of a transport control (TC) group: rats were transported from the holding room to the experimental room on a cart in their covered home cages (as were the rats trained on the track) and killed 5 min later. Forty-three adult male rats were divided into six experimental groups: CC $(n=5)$, TC $(n=8), 1 \mathrm{~L}-1 \mathrm{D}(n=9), 4 \mathrm{~L}-1 \mathrm{D}(n=8)$, $1 \mathrm{~L}-4 \mathrm{D}(n=8)$, and $4 \mathrm{~L}-4 \mathrm{D}(n=5)$ (Fig. $1 b)$. On the experimental day, the time spent on the track for the different groups was as follows: 1L-1D, mean of 83 s, range of 35-217 s; 4L-1D, mean of 249 s, range of $117-367 \mathrm{~s} ; 1 \mathrm{~L}-4 \mathrm{D}$, mean of $103 \mathrm{~s}$, range of $24-242$ s; and 4L-4D, mean of 169 s, range of 95-249 s (supplemental Fig. $\mathrm{S} 2 a$, available at www.jneurosci.org as supplemental material). The mean total time spent on the track over $4 \mathrm{~d}$ was 403 and $702 \mathrm{~s}$ for the 1L-4D and 4L-4D groups, respectively (supplemental Fig. S2b, available at www.jneurosci.org as supplemental material).

Active transcription of $A r c$ was detected in hippocampal CA3 and CA1 neurons as discrete intranuclear foci of FISH signal from $A r c$-intron-enriched riboprobe (see Materials and Methods) (Guzowski et al., 1999, 2005, 2006) (Fig. 3a,b) (supplemental Figs. S3, S4, available at www.jneurosci.org as supplemental material). One-way ANOVA on the proportions of $A r c$ transcribing neurons $\left(\mathrm{Arc}^{+}\right)$in CA3 revealed a significant overall effect of the experimental group $\left(F_{(5,37)}=11.57, p<0.0001\right)$ (Fig. 3c). Post hoc analysis revealed a that 1L-1D increased the proportion of $\mathrm{Arc}^{+} \mathrm{CA} 3$ neurons (9\%) compared with the CC or TC groups ( 2 and $4 \%$, respectively; $p<0.01$ and $p<0.05$ for respective comparisons). Extended experience on the track, whether $4 \mathrm{~L}-1 \mathrm{D}(10 \%), 1 \mathrm{~L}-4 \mathrm{D}(10 \%)$, or $4 \mathrm{~L}-4 \mathrm{D}(12 \%)$ did not alter the proportions of $\mathrm{Arc}^{+} \mathrm{CA} 3$ neurons compared with a single lap on a single day (all comparisons $p>0.05$ ).

Similar to CA3, a significant effect of experimental condition on the proportion of $A r c^{+}$neurons was observed in CA1 $\left(F_{(5,37)}\right.$ $=51.31, p<0.0001)$. Post hoc analysis revealed increased proportion of $\mathrm{Arc}^{+} \mathrm{CA} 1$ neurons relative to both control groups (CC and TC) after a single lap around the track for the first time (1L-1D, 21\%; $p<0.001$ for both comparisons) (Fig. 3d). 4L-1D induced Arc transcription in 30\% of CA1 neurons, which was significantly higher than $1 \mathrm{~L}-1 \mathrm{D}(p<0.001)$. $1 \mathrm{~L}-4 \mathrm{D}$ rats $(28 \%)$ showed a higher proportion of $\mathrm{Arc}^{+}$neurons compared with the 1L-1D group, but this did not reach statistical significance $(p=$ 0.13). Finally, $4 \mathrm{~L}-4 \mathrm{D}$ induced $A r c$ in yet a higher proportion of CA1 neurons (36\%) compared with the other track-trained groups, but this value only reached statistical significance when compared with the $1 \mathrm{~L}-1 \mathrm{D}$ group $(p<0.0001)$ (Fig. $3 d)$. The transport to a different room did not induce Arc transcription that was significantly higher than the caged control (CC and TC, 2 vs $9 \%$, respectively; $p=0.32$ ). This result demonstrated that the dramatic increase in the proportion of $\mathrm{Arc}^{+}$cells in trained rats resulted from the experience on the track and not from handling and/or transport.

The proportion of $\mathrm{Arc}^{+}$neurons from the groups trained on the track indicate that the total number of laps around the track, rather than the time spent on the track, either on the testing day alone or in total, was the best predictor of Arc expression in CA1 (Pearson's correlation, $r^{2}=0.461, p<0.0001$ ) (Fig. 3f) (supplemental Fig. S2d,f, available at www.jneurosci.org as supplemental material). Conversely, the proportion of $\mathrm{Arc}^{+} \mathrm{CA} 3$ neurons did not correlate with either the number of laps (Fig. $3 e$ ) or time spent on the track (supplemental Fig. S2c,e, available at www. jneurosci.org as supplemental material).

The above analyses used a threshold-based approach (see Materials and Methods) (Guzowski et al., 2006) to classify neurons 

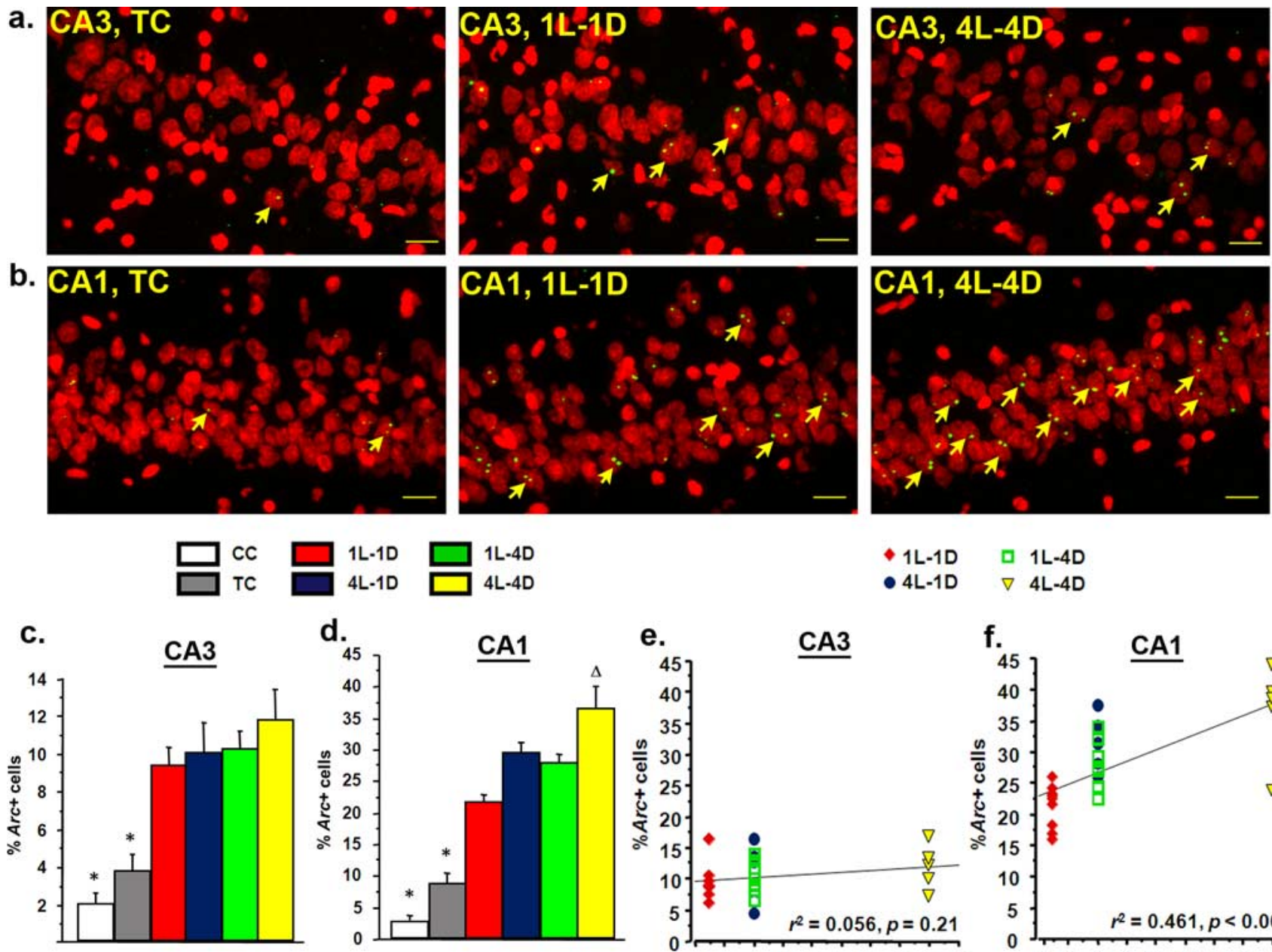

e.

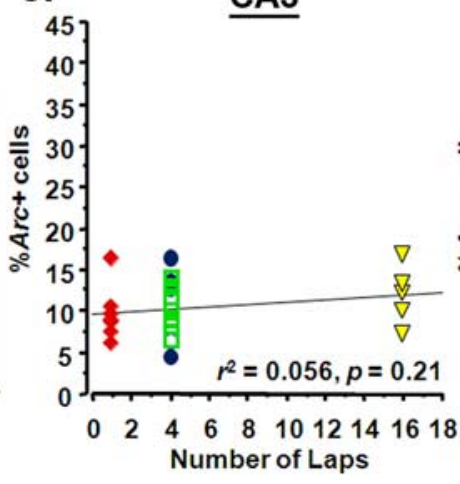

f.

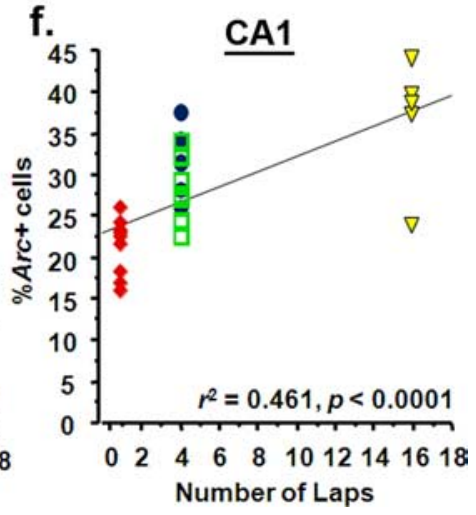

Figure 3. Dynamics of hippocampal ensemble recruitment in the behaving rat: robust activation of CA3 by limited experience and incremental activation of $\mathrm{CA} 1$ with extended experience. Quantification of Arc-positive CA3 and CA1 neurons from rats trained on the rectangular track. $a$, A confocal projection image of the CA3 region from a TC, 1L-1D, and 4L-4D rat. Yellow arrows indicate cells containing Arc transcription foci (green color) within a nucleus (red color). Scale bars, $20 \mu \mathrm{m}$. $\boldsymbol{b}$, A confocal projection image of the CA1 region from a TC, 1L-1D, and 4L-4D rat. $\boldsymbol{c}$, The percentages of $\mathrm{ArC}^{+} \mathrm{CA} 3$ neurons (mean $\pm \mathrm{SEM}$ ) for the six groups. Arc ${ }^{+}$neurons of the track-trained rats were significantly higher than those of both control groups but did not differ from each other. ${ }^{*} p<$ 0.05 , different from all of the track-trained groups; $n=5-9$ rats per group. $\boldsymbol{d}$, The percentages of $\operatorname{Arc}^{+}$CA1 neurons (mean $\pm \mathrm{SEM}$ ) for the six groups. Similar to $C A 3$, the proportions of $A \mathrm{Cr}^{+}$neurons of the track-trained animals were significantly higher than those of controls. However, in contrast to $C A 3$, the proportion of $\operatorname{Arc}^{+}$neurons incremented with increased experience on the track. ${ }^{*} p<$ 0.05 , different from all track-trained groups; ${ }^{\Delta} p<0.05$, different from 1L-1D; $n=5-9$ rats per group. $\boldsymbol{e}$, The proportion of $\operatorname{Arc}^{+}$cells in CA3 did not correlate with number of laps completed on the track. Pearson's correlation coefficient and $p$ values are shown. $f$, The proportion of $\mathrm{Arc}^{+}$cells in CA1 correlated with number of laps completed on the track. Pearson's correlation coefficient and $p$ values are shown.

as either $\mathrm{Arc}^{+}$or $\mathrm{Arc}^{-}$. This method allowed comparisons of the amount of intronic RNA signal detected per positive or negative cell across the different behavioral groups (supplemental Fig. 4, available at www.jneurosci.org as supplemental material). As shown in Figure $4 a$, virtually no FISH signal was found in CA3 Arc cells $(n=15,066$ cells, median of 27 for all track-trained groups combined) compared with $\mathrm{Arc}^{+}$cells ( $n=1655$ cells, median of 1685 for all groups). These data indicate that Arc transcription is not detectable in quiescent neurons and is induced in a dramatic manner in neurons specifically recruited to an active ensemble. A comparison of Arc signal intensity per positive CA3 neuron did not reveal differences across the behaviorally trained groups (Kruskal-Wallis test, $H_{3}=4.48, p=0.21$ ). Arc signal intensity in positive CA1 neurons was also dramatically higher ( $n=5613$ cells, median of 1365) than that in negative neurons $(n=14,092$ cells, median of 19$)$ (Fig. $4 b)$. In contrast to CA3, the comparison of Arc signal in CA1-positive neurons revealed a significant effect of behavioral training condition $\left(H_{3}=93.77, p<\right.$
0.0001). Mann-Whitney $U$ tests revealed that signal intensity of CA1 $\mathrm{Arc}^{+}$neurons in the $1 \mathrm{~L}-1 \mathrm{D}$ group (median of 1157) was significantly lower than all other behavioral groups: $4 \mathrm{~L}-1 \mathrm{D}$, median of $1436, Z=-7.8, p<0.0001 ; 1 \mathrm{~L}-4 \mathrm{D}$, median of $1359, Z=$ $-6.9, p<0.0001$; and $4 \mathrm{~L}-4 \mathrm{D}$, median of $1502, Z=-8.8, p<$ 0.0001 . Arc signal intensity per positive CA1 neurons in the $4 \mathrm{~L}-4 \mathrm{D}$ group also differed significantly from the $4 \mathrm{~L}-1 \mathrm{D}(Z=$ $-2.1, p<0.05)$ and $1 \mathrm{~L}-4 \mathrm{D}(Z=-2.7, p<0.01)$ groups. Last, Arc intensity per positive neuron in the $4 \mathrm{~L}-1 \mathrm{D}$ and $1 \mathrm{~L}-4 \mathrm{D}$ groups did not differ from each other $(Z=-2.1, p=0.26)$. These data suggest that, in CA1, and not in CA3, Arc transcription at the cellular level occurred in a graded manner with extended experience on the track.

Inactivation of the medial septum abolishes behavioral induction of Arc transcription in CA1 and CA3 neurons To test whether location-specific cell firing is sufficient to induce Arc transcription in CA1 and CA3 neurons, we implanted rats 

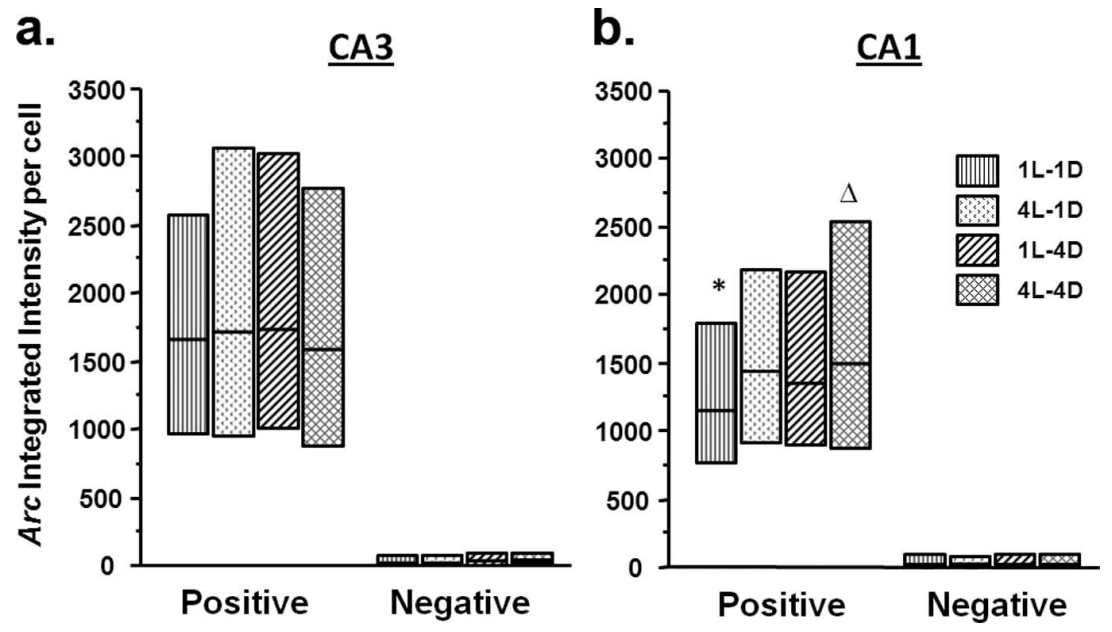

Figure 4. Activation of Arc transcription in single CA3 and CA1 neurons. $\boldsymbol{a}, \boldsymbol{b}$, The comparison of integrated fluorescent intensities (median and interquartile range) for $\mathrm{Arc}^{+}$and $\mathrm{Arc}^{-}$cells from the track trained groups in CA3 (a) and CA1 (b). Note the virtual lack of signal in $\mathrm{Arc}^{-}$cells and the dramatic levels in $\mathrm{Arc}^{+}$cells. Whereas the intensities of $\mathrm{Arc}^{+}$signals did not differ across the training groups in $\mathrm{CA} 3, \mathrm{Arc}^{+}$signal in $1 \mathrm{~L}-1 \mathrm{D}$ group was significantly lower than the other three training groups in $\mathrm{CA} 1\left(^{*} p<\right.$ 0.0001 compared with all other three groups; ${ }^{\Delta} p<0.05$ compared with $4 \mathrm{~L}-1 \mathrm{D}$ and $\left.1 \mathrm{~L}-4 \mathrm{D}\right)$.

with guide cannulas aimed at the medial septum and then trained them to walk on the track for four laps a day, for 4 consecutive days. On the last day of training (day 4 ), each rat received an infusion $(0.5 \mu \mathrm{l})$ of either TETRA ( $2 \%$ in PBS) or PBS (VEH) into the medial septum and was trained on the track 5 min later (TRACK) or left in its home cage (CC) (Fig. 5a). The tracktrained groups (VEH-TRACK and TETRA-TRACK) spent a similar time on the track, both on the last day $(p=0.12$; data not shown) and over the $4 \mathrm{~d}$ ( $p=0.45$; data not shown). After the animals were killed, the brains were processed for $A r c$-intron FISH (Fig. 5b,c) (supplemental Fig. S5, available at www. jneurosci.org as supplemental material). A two-way ANOVA of the proportions of $\mathrm{Arc}^{+} \mathrm{CA} 1$ neurons revealed significant main effects of the experimental condition (CC or TRACK, $F_{(1,14)}=$ $12.55, p<0.01$ ), the infusion (VEH or TETRA, $F_{(1,14)}=15.01$, $p<0.01)$, and an interaction $\left(F_{(1,14)}=7.51, p<0.05\right)$. Post hoc analyses showed that the vehicle-infused rats that received training (VEH-TRACK; $n=6$ ) displayed a substantially greater proportion of $\mathrm{Arc}^{+} \mathrm{CA1}$ neurons (30\%) compared with all other groups (VEH-CC, $9 \%, n=4$; TETRA-CC, $6 \%, n=3$; and TETRA-TRACK, $8 \%, n=5 ; p<0.01$ for all comparisons) (Fig. $5 c, e)$. Similar effects were observed in CA3, with two-way ANOVA revealing significant main effects of the experimental condition $\left(F_{(1,14)}=6.99, p<0.05\right)$, the infusion $\left(F_{(1,14)}=16.61\right.$, $p<0.01)$, and an interaction $\left(F_{(1,14)}=5.48, p<0.05\right)$. Post hoc analyses showed that, as in CA1, a greater proportion of $\mathrm{Arc}^{+}$ CA3 neurons (13\%) was observed in the VEH-TRACK group compared with the VEH-CC, TETRA-CC, and TETRA-TRACK groups $(6,3$, and $3 \%$, respectively; $p<0.01$ for all comparisons) (Fig. 5b,d). Notably, visual inspection revealed that septal inactivation did not grossly alter Arc induction in the overlying neocortex of track-trained rats (supplemental Fig. S5, available at www.jneurosci.org as supplemental material) (compare VEHTRACK with TETRA-TRACK), demonstrating that septal inactivation produced a localized effect in the hippocampus, as predicted.

\section{Activation of IEG transcription in CA1 neurons by LTP induction}

The finding that septal inactivation blocked experiencedependent $A r c$ induction in hippocampal neurons provides sup- port for the idea that IEG transcription is coupled to plasticity-inducing stimuli. However, this notion is in contrast with a previous study that failed to detect IEG upregulation in CA1 neurons after LTP induction (French et al., 2001). To reexamine the relationship between IEG transcription and LTP, we administered highfrequency stimulation (HFS) (two $100 \mathrm{~Hz}$ trains lasting $500 \mathrm{~ms}$ ) or test stimuli unilaterally in CA3 of anesthetized rats. All rats were killed $5 \mathrm{~min}$ later, and their brains were processed using FISH with Arc and zif268 intron-enriched riboprobes (Fig. 6d). HFS in CA3 elicited synaptic potentiation in contralateral CA1 (see Materials and Methods) (Figs. $6 a-c$ ) and activated $A r c$ and zif268 transcription in high proportions of $(\sim 80 \%)$ of contralateral and ipsilateral CA1 neurons, whereas the test stimulus did not (Fig. 6d). Our findings contrast strongly with the previous study (French et al., 2001), which failed to detect changes in Arc or zif268 RNA expression in CA1 of rats killed $0.5-1 \mathrm{~h}$ after LTP induction using autoradiographic in situ hybridization with end-labeled oligodeoxynucleotide probes. The positive results demonstrated here using the same LTP induction protocol indicate that the previous negative finding was likely attributable to use of a less sensitive in situ method and collection of tissue at a suboptimal time point after LTP induction.

\section{Discussion}

The most striking finding reported here is that experience as limited as a single traverse around the rectangular track was sufficient to trigger Arc transcription in complete CA3 ensembles but not in CA1 (Fig. 3). In addition, behaviorally induced Arc transcription in hippocampal neurons was shown to critically require medial septal input (Fig. 5), linking Arc transcription to plasticity-inducing stimuli and not simply cell firing activity. These findings demonstrate that IEG transcription necessary for long-lasting plasticity is activated in the entire CA3 ensemble within a single stimulus presentation, providing a mechanistic basis for CA3 in one-trial learning.

The complete recruitment of the CA3 ensemble after a single lap (Fig. 3c) may derive from faster development and greater coherence of ensemble representations resulting from the dense recurrent connectivity in CA3 (MacVicar and Dudek, 1980; Miles and Wong, 1986). Our data are consistent with rapid engagement of plastic mechanisms by CA3 neurons after an initial exposure to a changed environment (Lee et al., 2004). Given the critical role of Arc in synaptic plasticity (Guzowski et al., 2000; Plath et al., 2006; Messaoudi et al., 2007), robust Arc induction in rapidly established CA3 ensembles provides a means for rapid encoding of single-trial experiences (Lee and Kesner, 2002; Nakazawa et al., 2003).

In contrast to $\mathrm{CA} 3$, increasing the number of laps around the track augmented the proportion of $\mathrm{Arc}^{+} \mathrm{CA1}$ neurons (Fig. $3 d$ ). After a total of 16 laps over $4 \mathrm{~d}(4 \mathrm{~L}-4 \mathrm{D})$, the percentage of $\mathrm{Arc}^{+}$ CA1 neurons was similar to that observed after 5 min of openfield exploration (Guzowski et al., 1999, 2006; Vazdarjanova et al., 2002; Vazdarjanova and Guzowski, 2004). The incremental increase in the proportion of $\mathrm{Arc}^{+} \mathrm{CAl}$ neurons suggests that, although a single lap is sufficient to induce $A r c$ transcription in many neurons, more extensive sampling of the environment is 
required for complete recruitment of the ensemble. These data are consistent with recording studies showing partial activation of CA1 ensembles during the initial exposure to an environment (Hill, 1978; Frank et al., 2004) and with the idea that plastic changes in CA1 place cell activity require extended experience in an altered environment (Wilson and McNaughton, 1993; Lee et al., 2004). The similar regulation of Arc transcription and place cell plasticity in CA1 neurons strengthens the idea that IEG transcription is reliably linked to plasticity-inducing stimuli, as discussed further below. A recent study demonstrated that hippocampal LTP can be induced by a single burst of spikes in CA1 (Remy and Spruston, 2007). Together with this past study, our data showing that a significant proportion of CA1 neurons activates $A r c$ transcription after a single lap suggest that brief experiences can be readily and rapidly stored in CA1 (and CA3) via IEG-dependent LTP-like plasticity, which may serve to stabilize (consolidate) information-specific place cell representations in CA1 (and CA3) ensembles.

Continued Arc induction in CA1 over days of training (Fig. $3 d$ ) is consistent with previous findings that the proportion of $\mathrm{Arc}^{+}$CA1 neurons were similar in rats exposed to an open field for 5 min either once or over 9 consecutive days (Guzowski et al., 2006). Here we extend these findings to show that, like in CA1, Arc transcription remains coupled to behavioral experience in CA3 neurons (Fig. 3c). This finding is at odds with the idea that plastic changes involved in memory formation cease after initial learning is completed, and a memory trace becomes "stable." If this idea were true, then IEG transcription should diminish in the absence of new learning (i.e., after several exposures to the same environment). However, the repeated activation of Arc (and c-fos and zif268) (Fig. 2 ) in a familiar environment, together with the critical role of Arc critical role in plasticity and learning (Guzowski et al., 2000;

Plath et al., 2006; Messaoudi et al., 2007), suggests that neural activity accompanying behavior continues to trigger plastic changes in the hippocampus to allow updating of memory traces.

The analysis of Arc transcription at the single-cell level revealed differences between CA3 and CA1 (Fig. 4). Similar to the pattern of CA3 ensemble recruitment (Fig. $3 a, c, e$ ), the levels of Arc signal per positive CA3 neuron in the $1 \mathrm{~L}-1 \mathrm{D}$ group were equivalent to the other track-trained groups (Fig. $4 a$ ). Thus, a single traverse through the firing field resulted in efficient Arc transcription. In contrast, Arc signal per positive CA1 neuron of the track-trained groups was lowest in the $1 \mathrm{~L}-1 \mathrm{D}$ group and increased with additional experience (Fig. 4b). Although the basis for the more rapid engagement of $A r c$ transcription in CA3 neurons by a single lap is not clear at this time, it supports the notion
= a lap around the track
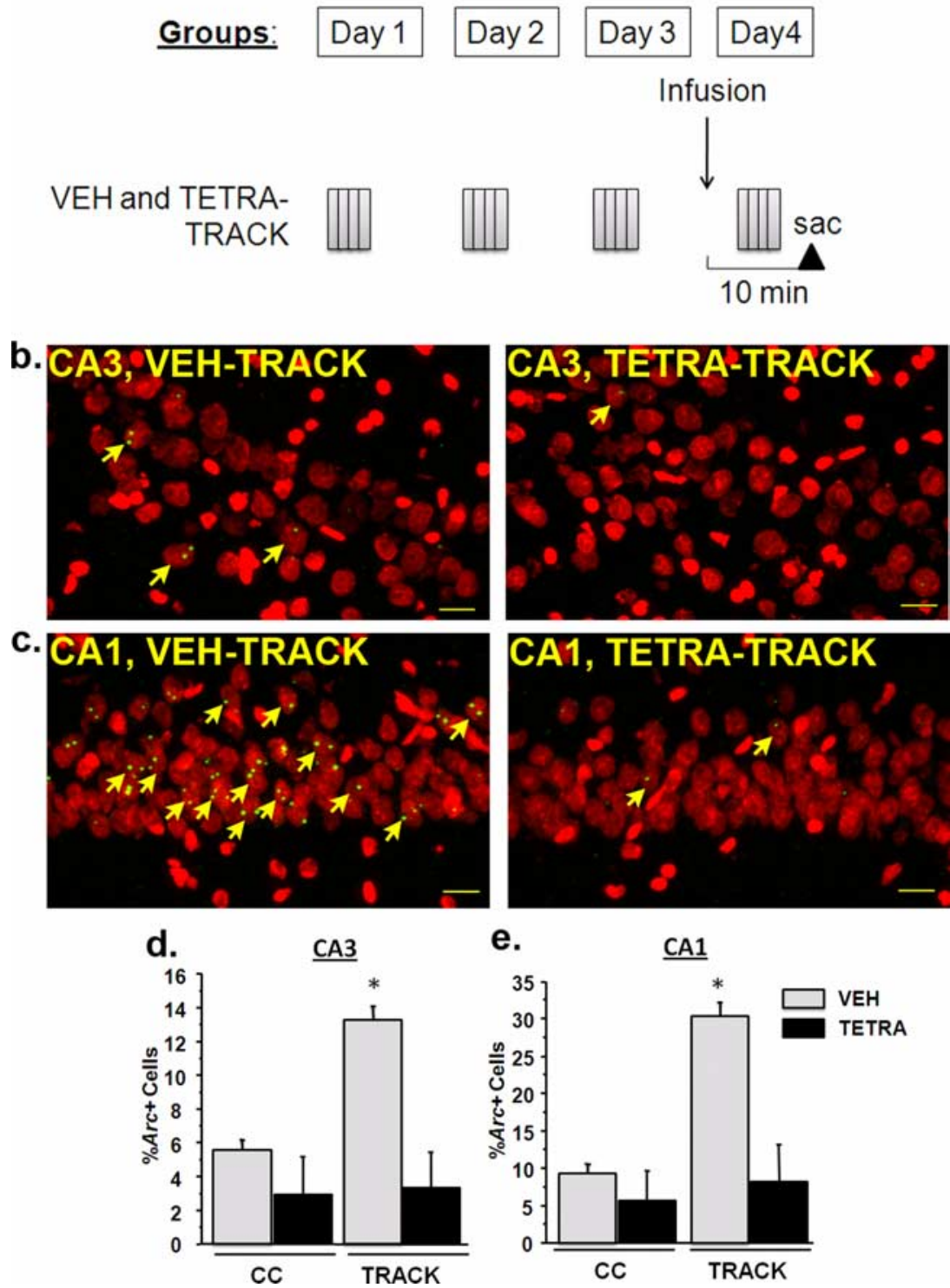

e.

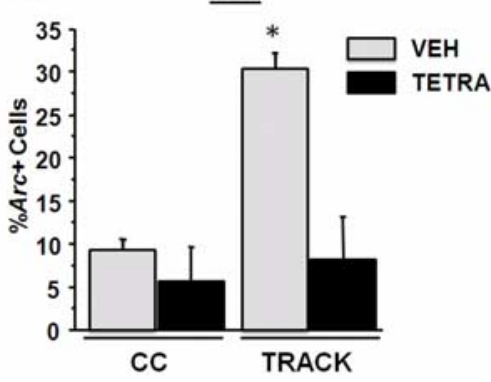

$\underline{\mathrm{CA} 1}$

5. Medial septal inactivation by infusion of tetracaine abolished behavioral induction of Arc in CA3 and CA1 neurons. $\boldsymbol{a}$

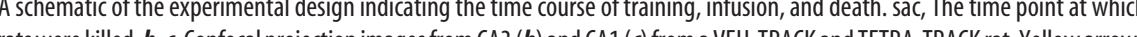
rats were killed. $\boldsymbol{b}, \boldsymbol{c}$, Confocal projection images from CA3 (b) and CA1 (c) from a VEH-TRACK and TETRA-TRACK rat. Yellow arrows (d) and CA1 (e), the percentage of $\operatorname{Arc}^{+}$neurons (mean \pm SEM) in the VEH-TRACK group was significantly higher than in all three other groups. ${ }^{*} p<0.0001$, different from all other behavioral groups in $\boldsymbol{a} ;{ }^{*} p<0.001$ in $\boldsymbol{b} ; n=3-6$ rats per group.

that CA3, both at ensemble and cellular levels, is particularly well suited for encoding one-trial experience.

Behavioral induction of Arc transcription in CA1 and CA3 neurons was abolished by inactivation of the medial septum (Fig. 5). Similar inactivations eliminate theta oscillations (Rawlins et al., 1979; Mitchell et al., 1982; Lee et al., 1994), interfere with LTP induction in the hippocampus (Rashidy-Pour et al., 1996), and disrupt hippocampus-dependent learning and memory (Mitchell et al., 1982; Hagan et al., 1988; McNaughton et al., 2006). Medial septal inactivation, however, spares location-specific firing in CA1 place cells and disrupts such firing in 50\% of CA3 place cells (Mizumori et al., 1989a,b). Together with these previous electrophysiological studies, the current findings provide evidence that location-specific cell firing is not sufficient to activate 


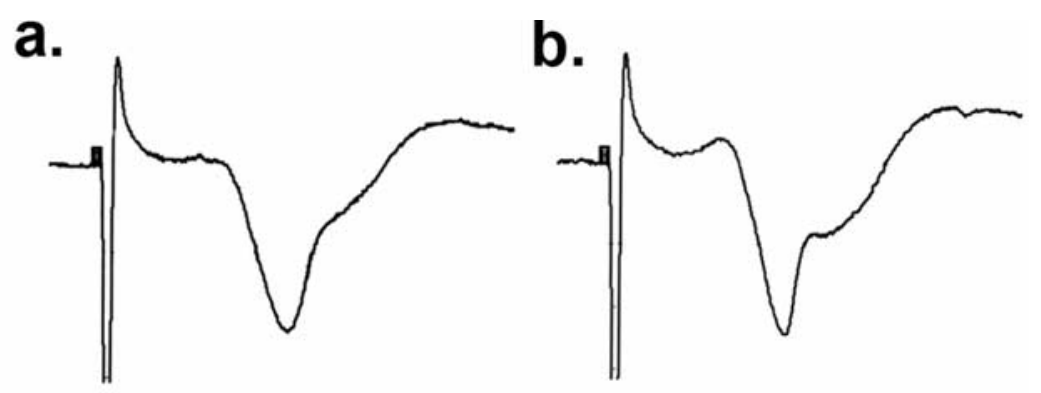

C.
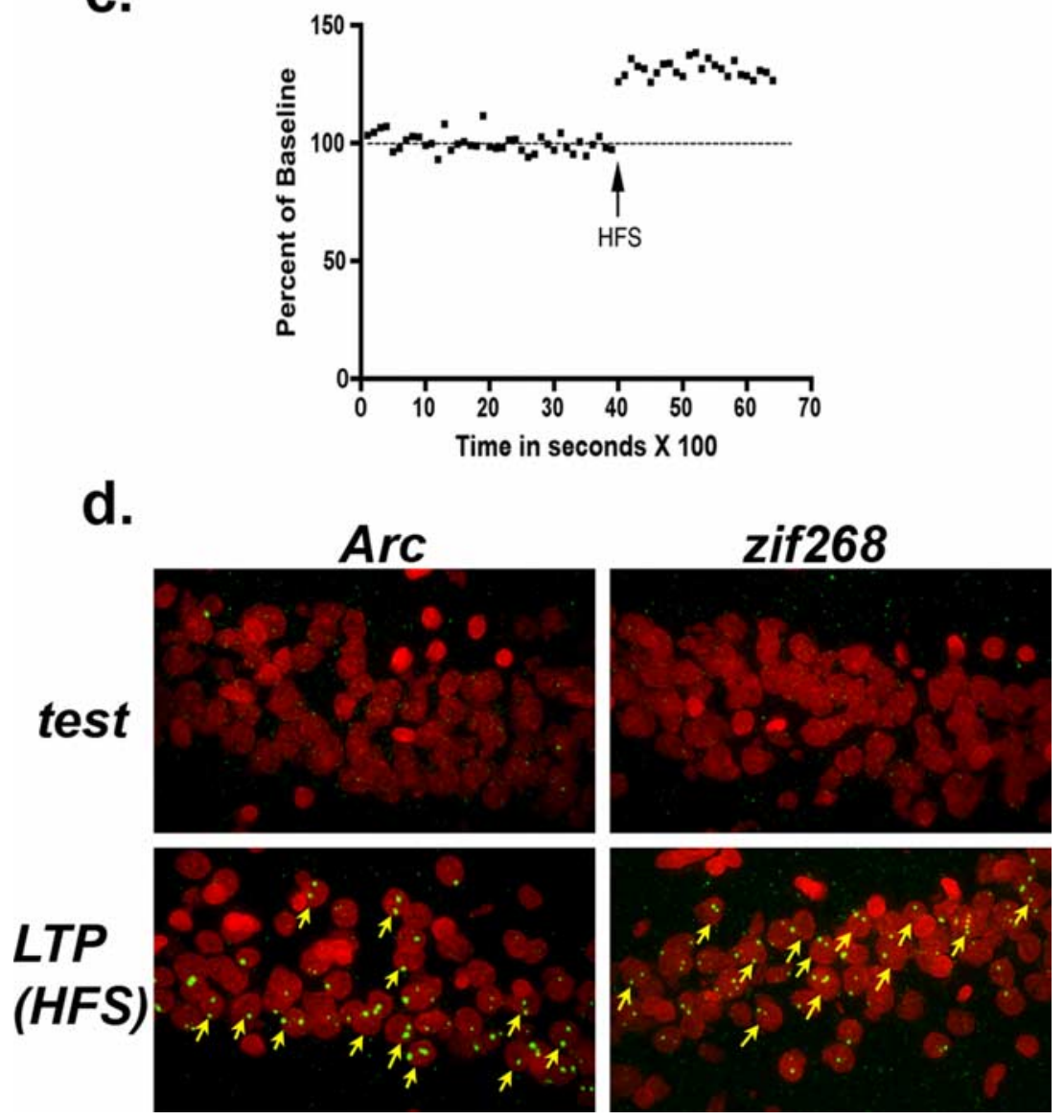

Figure 6. Activation of IEG transcription in CA1 neurons by LTP-inducing stimulation. $\boldsymbol{a}, \boldsymbol{b}$, Traces illustrating negative-going population EPSPs recorded by a micropipette positioned in CA1 contralateral from the stimulating electrode in CA3 at baseline $(\boldsymbol{a})$ and after HFS ( $\boldsymbol{b} ; 2$ 100-Hz trains separated by 30 s). $\boldsymbol{c}$, Population-spike amplitude as a percentage of baseline before and after HFS stimulation. $\boldsymbol{d}$, Confocal projection images of the contralateral CA1 show that LTP stimulation (HFS) activated transcription of Arc and zif268, whereas the test stimulus did not. Similar results were seen in ipsilateral CA1 neurons (data not shown). Yellow arrows indicate cells containing Arc transcription foci (green color) within a nucleus (red color).

Arc transcription but rather that Arc expression is tightly linked to neural activity associated specifically with synaptic plasticity and memory.

Given that place cell activity accompanying an animal's behavior per se is not sufficient for Arc induction, what is the critical contribution of medial septal input in regulating Arc transcription in hippocampus? Similar to septal inactivations, permanent lesions of the fornix eliminate hippocampal theta and block behavioral induction of $A r c$ and other IEGs in hippocampus, without eliminating place cell activity (Miller and Best, 1980; Shapiro et al., 1989; Vann et al., 2000; Taubenfeld et al., 2001; Fletcher et al., 2006). In contrast, selective cholinergic lesions of the medial septum reduce, but do not eliminate, hippocampal theta and do not affect $A r c$ induction (Fletcher et al., 2007). The most parsimonious account of the previous and present data is that medial septal inactivation blocked behavioral induction of Arc transcription by removing theta oscillations, which may provide a critical timing metric for presynaptic and postsynaptic activity (Stewart and Fox, 1990; Vinogradova, 1995; Buzsáki, 2002). Longterm memory impairments after septal inactivation or fornix lesion are likely attributable, at least in part, to loss of IEG expression.

The loss of Arc induction in hippocampus after medial septal inactivation (Fig. 5) and the dramatic activation of IEG transcription by LTP stimulation (Fig. 6) reinforce the link between IEG expression and synaptic plasticity. In this context, Arc has been shown to be critical for LTP maintenance (Guzowski et al., 2000; Messaoudi et al., 2007), possibly through regulation of dendritic actin dynamics (Messaoudi et al., 2007). Furthermore, the recurring coupling of IEG expression to ongoing experience supports the view that hippocampal representations, of even familiar environments, remain plastic. A role for Arc in homeostatic synaptic scaling (Rial Verde et al., 2006; Shepherd et al., 2006) by facilitating endocytosis of AMPA receptors (Chowdhury et al., 2006) has been suggested by recent in vitro studies. Such an Arc-dependent synaptic scaling process in CA1 and CA3 neurons coupled to ongoing behavior may be necessary to prevent saturation of the system and optimize network stability to allow efficient encoding of new information. The current findings support the conclusion that, at the time of place cell firing and ensemble recruitment, molecular mechanisms are engaged to enable consolidation of cellular representations of experience. In particular, Arcinduction in the full CA3 ensemble after extremely brief experience (a single lap) provides a mechanism for encoding of one-trial experience.

\section{References}

Abraham WC, Dragunow M, Tate WP (1991) The role of immediate early genes in the stabilization of long-term potentiation. Mol Neurobiol 5:297-314.

Acsády L, Káli S (2007) Models, structure, function: the transformation of cortical signals in the dentate gyrus. Prog Brain Res 163:577-599.

Bozon B, Davis S, Laroche S (2002) Regulated transcription of the immediate-early gene Zif268: mechanisms and gene dosage-dependent function in synaptic plasticity and memory formation. Hippocampus 12:570-577.

Buzsáki G (2002) Theta oscillations in the hippocampus. Neuron 33:325-340.

Chawla MK, Lin G, Olson K, Vazdarjanova A, Burke SN, McNaughton BL, Worley PF, Guzowski JF, Roysam B, Barnes CA (2004) 3D-catFISH: a system for automated quantitative three-dimensional compartmental analysis of temporal gene transcription activity imaged by fluorescence in situ hybridization. J Neurosci Methods 139:13-24.

Chowdhury S, Shepherd JD, Okuno H, Lyford G, Petralia RS, Plath N, Kuhl D, 
Huganir RL, Worley PF (2006) Arc/Arg3.1 interacts with the endocytic machinery to regulate AMPA receptor trafficking. Neuron 52:445-459.

Fletcher BR, Calhoun ME, Rapp PR, Shapiro ML (2006) Fornix lesions decouple the induction of hippocampal arc transcription from behavior but not plasticity. J Neurosci 26:1507-1515.

Fletcher BR, Baxter MG, Guzowski JF, Shapiro ML, Rapp PR (2007) Selective cholinergic depletion of the hippocampus spares both behaviorally induced Arc transcription and spatial learning and memory. Hippocampus 17:227-234.

Frank LM, Stanley GB, Brown EN (2004) Hippocampal plasticity across multiple days of exposure to novel environments. J Neurosci 24:7681-7689.

French PJ, O'Connor V, Jones MW, Davis S, Errington ML, Voss K, Truchet B, Wotjak C, Stean T, Doyère V, Maroun M, Laroche S, Bliss TV (2001) Subfield-specific immediate early gene expression associated with hippocampal long-term potentiation in vivo. Eur J Neurosci 13:968-976.

Guzowski JF, McNaughton BL, Barnes CA, Worley PF (1999) Environment-specific expression of the immediate-early gene Arc in hippocampal neuronal ensembles. Nat Neurosci 2:1120-1124.

Guzowski JF, Lyford GL, Stevenson GD, Houston FP, McGaugh JL, Worley PF, Barnes CA (2000) Inhibition of activity-dependent arc protein expression in the rat hippocampus impairs the maintenance of long-term potentiation and the consolidation of long-term memory. J Neurosci 20:3993-4001.

Guzowski JF, Knierim JJ, Moser EI (2004) Ensemble dynamics of hippocampal regions CA3 and CA1. Neuron 44:581-584.

Guzowski JF, Timlin JA, Roysam B, McNaughton BL, Worley PF, Barnes CA (2005) Mapping behaviorally relevant neural circuits with immediateearly gene expression. Curr Opin Neurobiol 15:599-606.

Guzowski JF, Miyashita T, Chawla MK, Sanderson J, Maes LI, Houston FP, Lipa P, McNaughton BL, Worley PF, Barnes CA (2006) Recent behavioral history modifies coupling between cell activity and Arc gene transcription in hippocampal CA1 neurons. Proc Natl Acad Sci U S A 103:1077-1082.

Hagan JJ, Salamone JD, Simpson J, Iversen SD, Morris RG (1988) Place navigation in rats is impaired by lesions of medial septum and diagonal band but not nucleus basalis magnocellularis. Behav Brain Res 27:9-20.

Hill AJ (1978) First occurrence of hippocampal spatial firing in a new environment. Exp Neurol 62:282-297.

Kubik S, Miyashita T, Guzowski JF (2007) Using immediate-early genes to map hippocampal subregional functions. Learn Mem 14:758-770.

Lee I, Kesner RP (2002) Differential contribution of NMDA receptors in hippocampal subregions to spatial working memory. Nat Neurosci 5:162-168.

Lee I, Rao G, Knierim JJ (2004) A double dissociation between hippocampal subfields: differential time course of CA3 and CA1 place cells for processing changed environments. Neuron 42:803-815.

Lee MG, Chrobak JJ, Sik A, Wiley RG, Buzsáki G (1994) Hippocampal theta activity following selective lesion of the septal cholinergic system. Neuroscience 62:1033-1047.

Lin G, Adiga U, Olson K, Guzowski JF, Barnes CA, Roysam B (2003) A hybrid $3 \mathrm{D}$ watershed algorithm incorporating gradient cues and object models for automatic segmentation of nuclei in confocal image stacks. Cytometry A 56:23-36.

MacVicar BA, Dudek FE (1980) Local synaptic circuits in rat hippocampus: interactions between pyramidal cells. Brain Res 184:220-223.

McIntyre CK, Miyashita T, Setlow B, Marjon KD, Steward O, Guzowski JF, McGaugh JL (2005) Memory-influencing intra-basolateral amygdala drug infusions modulate expression of Arc protein in the hippocampus. Proc Natl Acad Sci U S A 102:10718-10723.

McNaughton N, Ruan M, Woodnorth MA (2006) Restoring theta-like rhythmicity in rats restores initial learning in the Morris water maze. Hippocampus 16:1102-1110.

Mehta MR, Barnes CA, McNaughton BL (1997) Experience-dependent, asymmetric expansion of hippocampal place fields. Proc Natl Acad Sci U S A 94:8918-8921.

Messaoudi E, Kanhema T, Soulé J, Tiron A, Dagyte G, da Silva B, Bramham CR (2007) Sustained Arc/Arg3.1 synthesis controls long-term potentiation consolidation through regulation of local actin polymerization in the dentate gyrus in vivo. J Neurosci 27:10445-10455.

Miles R, Wong RK (1986) Excitatory synaptic interactions between CA3 neurones in the guinea-pig hippocampus. J Physiol 373:397-418.

Miller VM, Best PJ (1980) Spatial correlates of hippocampal unit activity are altered by lesions of the fornix and endorhinal cortex. Brain Res 194:311-323.
Mitchell SJ, Rawlins JN, Steward O, Olton DS (1982) Medial septal area lesions disrupt theta rhythm and cholinergic staining in medial entorhinal cortex and produce impaired radial arm maze behavior in rats. J Neurosci 2:292-302.

Miyashita T, Kubik S, Lewandowski G, Guzowski JF (2008) Networks of neurons, networks of genes: an integrated view of memory consolidation. Neurobiol Learn Mem 89:269-284.

Mizumori SJ, Barnes CA, McNaughton BL (1989a) Reversible inactivation of the medial septum: selective effects on the spontaneous unit activity of different hippocampal cell types. Brain Res 500:99-106.

Mizumori SJ, McNaughton BL, Barnes CA, Fox KB (1989b) Preserved spatial coding in hippocampal CA1 pyramidal cells during reversible suppression of CA3c output: evidence for pattern completion in hippocampus. J Neurosci 9:3915-3928.

Moga DE, Calhoun ME, Chowdhury A, Worley P, Morrison JH, Shapiro ML (2004) Activity-regulated cytoskeletal-associated protein is localized to recently activated excitatory synapses. Neuroscience 125:7-11.

Morris RG, Frey U (1997) Hippocampal synaptic plasticity: role in spatial learning or the automatic recording of attended experience? Philos Trans R Soc Lond B Biol Sci 352:1489-1503.

Nakazawa K, Sun LD, Quirk MC, Rondi-Reig L, Wilson MA, Tonegawa S (2003) Hippocampal CA3 NMDA receptors are crucial for memory acquisition of one-time experience. Neuron 38:305-315.

Plath N, Ohana O, Dammermann B, Errington ML, Schmitz D, Gross C, Mao X, Engelsberg A, Mahlke C, Welzl H, Kobalz U, Stawrakakis A, Fernandez E, Waltereit R, Bick-Sander A, Therstappen E, Cooke SF, Blanquet V, Wurst W, Salmen B, et al. (2006) Arc/Arg3.1 is essential for the consolidation of synaptic plasticity and memories. Neuron 52:437-444.

Rashidy-Pour A, Motamedi F, Semnanian S, Zarrindast MR, Fatollahi Y, Behzadi G (1996) Effects of reversible inactivation of the medial septal area on long-term potentiation and recurrent inhibition of hippocampal population spikes in rats. Brain Res 734:43-48.

Rawlins JN, Feldon J, Gray JA (1979) Septo-hippocampal connections and the hippocampal theta rhythm. Exp Brain Res 37:49-63.

Remy S, Spruston N (2007) Dendritic spikes induce single-burst long-term potentiation. Proc Natl Acad Sci U S A 104:17192-17197.

Rial Verde EM, Lee-Osbourne J, Worley PF, Malinow R, Cline HT (2006) Increased expression of the immediate-early gene arc/arg3.1 reduces AMPA receptor-mediated synaptic transmission. Neuron 52:461-474.

Shapiro ML, Simon DK, Olton DS, Gage FH 3rd, Nilsson O, Björklund A (1989) Intrahippocampal grafts of fetal basal forebrain tissue alter place fields in the hippocampus of rats with fimbria-fornix lesions. Neuroscience 32:1-18.

Shepherd JD, Rumbaugh G, Wu J, Chowdhury S, Plath N, Kuhl D, Huganir RL, Worley PF (2006) Arc/Arg3.1 mediates homeostatic synaptic scaling of AMPA receptors. Neuron 52:475-484.

Steward O, Worley PF (2001) Selective targeting of newly synthesized Arc mRNA to active synapses requires NMDA receptor activation. Neuron 30:227-240.

Stewart M, Fox SE (1990) Do septal neurons pace the hippocampal theta rhythm? Trends Neurosci 13:163-168.

Taubenfeld SM, Wiig KA, Monti B, Dolan B, Pollonini G, Alberini CM (2001) Fornix-dependent induction of hippocampal CCAAT enhancerbinding protein $\beta$ and $\delta$ colocalizes with phosphorylated cAMP response element-binding protein and accompanies long-term memory consolidation. J Neurosci 21:84-91.

Vann SD, Brown MW, Erichsen JT, Aggleton JP (2000) Using Fos imaging in the rat to reveal the anatomical extent of the disruptive effects of fornix lesions. J Neurosci 20:8144-8152.

Vazdarjanova A, Guzowski JF (2004) Differences in hippocampal neuronal population responses to modifications of an environmental context: evidence for distinct, yet complementary, functions of CA3 and CA1 ensembles. J Neurosci 24:6489-6496.

Vazdarjanova A, McNaughton BL, Barnes CA, Worley PF, Guzowski JF (2002) Experience-dependent coincident expression of the effector immediate-early genes Arc and Homer 1a in hippocampal and neocortical neuronal networks. J Neurosci 22:10067-10071.

Vinogradova OS (1995) Expression, control, and probable functional significance of the neuronal theta-rhythm. Prog Neurobiol 45:523-583.

Wilson MA, McNaughton BL (1993) Dynamics of the hippocampal ensemble code for space. Science 261:1055-1058. 